\title{
GRUPOS DE LAZER COMO CONTEXTOS DE DESENVOLVIMENTO
}

LEISURE GROUPS AS DEVELOPMENT CONTEXTS

GRUPOS DE OCIO COMO CONTEXTOS DE DESARROLLO

Manoela Pagotto Martins Nodari

Edinete Maria Rosa ${ }^{*}$

\begin{abstract}
RESUMO
Este estudo investigou as influências da participação em grupos de lazer no desenvolvimento de jovens de classes populares. Utilizou como aporte teórico a teoria bioecológica do desenvolvimento humano, com foco nos processos proximais estabelecidos dentro do grupo e em relação à família e amigos. Participaram da pesquisa 21 jovens, sendo 12 meninas e 9 meninos, com idades de 15 a 19 anos, estudantes de ensino médio em uma escola da rede pública. Os dados foram coletados por meio de entrevistas e organizados em categorias, baseadas no modelo PPCT. Como resultados principais, nota-se que as interaçôes estabelecidas pelos jovens dentro dos grupos promovem mudanças positivas em suas características pessoais e realçam suas percepções em relação a uma melhoria das interações nos contextos família e amigos. Conclui-se que o grupo tem se constituído como elemento positivo na vida desses jovens e como recurso favorecedor para seu desenvolvimento.
\end{abstract}

Palavras-chave: Juventude. Grupos de lazer. Teoria bioecológica. Desenvolvimento. Classe popular.

\section{ABSTRACT}

This study investigated the influences of participation in leisure groups on the development of underprivileged teenagers. Its theoretical basis is the bioecological theory of human development, focusing on proximal processes established within the group, also in relation with family and friends. Twenty-one teenagers took part in the survey, 12 female and 9 male, aged between 15 and 19 years old, which are high school students of a public school. The data were collected via interviews and organized into categories, according to the PPCT model. The major results show that the interactions established by the teenagers within the groups promote positive changes in their personal characteristics and enhance their perceptions regarding to an improvement in their interactions with family and friends. In conclusion,

Texto recebido em 9 de março de 2017 e aprovado para publicação em 4 de julho de 2018.

* Mestra pelo Programa de Pós-Graduação em Psicologia da Universidade Federal do Espírito Santo (PPGP/UFES). E-mail: manu_pagotto@yahoo.com.br

** Professora permanente no PPGP/UFES. E-mail: edineter@gmail.com 
the group has been a positive element in the lives of these teenagers and a favorable resource for their development.

Keywords: Youth. Leisure groups. Bioecological theory. Development. Underprivileged classes.

\title{
RESUMEN
}

Este estudio investigó las influencias de la participación en grupos de ocio en el desarrollo de jóvenes de clases populares. Se utilizó como contribución teórica la teoría bioecológica del desarrollo humano con foco en los procesos proximales establecidos dentro del grupo y con relación a la familia y amigos. Participaron de la investigación 21 jóvenes, siendo 12 niñas y 9 niños, con edades entre 15 y 19 años, estudiantes de la educación secundaria en una escuela de la red pública. Los datos fueron recolectados por medio de encuestas y organizados en categorías, basadas en el modelo PPCT. Como resultados principales, se nota que las interacciones establecidas por los jóvenes dentro de los grupos promueven cambios positivos en sus características personales y refuerzan sus relaciones en los contextos familia y amigos. Se concluye que el grupo se ha constituido como elemento positivo en la vida de esos jóvenes y como recurso favorecedor de su desarrollo.

Palabras clave: Juventud. Grupos de ocio. Teoría bioecológica. Desarrollo. Clase popular.

\section{INTRODUÇÃO}

\begin{abstract}
$s$ diversas questões que envolvem a juventude vêm alcançando destaque significativo tanto no âmbito nacional quanto internacional, por parte de 1 profissionais, pesquisadores, mídia, órgãos e instituições, sejam públicos ou não governamentais. Duas linhas de pensamento principais têm pautado com maior frequência as abordagens sobre o tema:
\end{abstract}

1) a noção de juventude como fase preparatória da vida, especialmente para jovens em posição privilegiada, que podem adiar a independência em relação a suas famílias e estender sua formação educacional para, então, colocarem-se no mercado de trabalho;

2) a noção de juventude como fase problemática, principalmente nas abordagens sobre jovens de classes populares, que carregam consigo o estigma por pertencerem a um estrato social identificado com a criminalidade e quase sempre se veem 
associados a condutas negativas e de risco, o que contribui para caracterizá-los a partir de uma ótica pessimista (Aquino, 2009; Dutra-Thomé e Koller, 2014; Franch, 2000).

Para além das representações que consideram a criminalidade como única forma de existência entre jovens de baixa renda, há diversas outras formas de ser (não necessariamente ligadas à violência) que fazem parte de seu cotidiano. Nesse sentido, os estudos que se dedicam a compreender as múltiplas dinâmicas estabelecidas no âmbito do tempo livre apresentam-se como um contraponto às frequentes associações entre juventude e violência, lançando luz sob outros aspectos de suas vidas (Franch, 2000). Entre esses aspectos, destaca-se a participação dos jovens em grupos de lazer, que ganham relevo conforme se adéquam às demandas e interesses desse segmento e se constituem como espaços privilegiados para a construção de suas identidades e exercício da sociabilidade (Aquino, 2009; Miranda, Souza Filho, \& Santiago, 2014; Sebenello, Keitel, \& Kleba, 2016).

$\mathrm{Na}$ literatura, o engajamento em atividades de lazer realizadas em grupo tem sido compreendido como favorecedor de um desenvolvimento positivo. O contato com outros jovens que compartilham gostos e interesses semelhantes mostra-se propício não somente para a afirmação/reafirmação de laços de amizade como também para o desenvolvimento da autonomia, protagonismo, criatividade e para a construção de laços de solidariedade e cooperação (Marques, Dell'Aglio, \& Sarriera, 2009; Prates, 2012). O pertencimento a um grupo, sobretudo nas comunidades de baixa renda, funciona, muitas vezes, como suporte positivo na vida dos jovens e como importante mecanismo de superação do estigma que carregam por sua procedência geográfica e social (Franch, 2000; Marques, Dell'Aglio, \& Sarriera, 2009).

Os grupos de lazer juvenis nas comunidades populares tendem a se organizar, principalmente, sob duas formas: a partir de instituiçôes formais, ou ainda, de maneira espontânea. Para Franch (2000), os espaços formais de lazer presentes nessas comunidades (grupos da igreja, escolas de música, agremiações esportivas, programas sociais, etc.) cumprem um importante papel, pois são eles, muitas vezes, que dão sentido à vida dos jovens e lhes abrem novas possibilidades. No entanto Franch (2000) enfatiza a necessidade de desvencilhar esses espaços da ideia de "salvação" da juventude de baixa renda, o que acaba reduzindo sua atuação a uma perspectiva de controle e domesticação do tempo (Schutz, Calza, \& Howes, 2012; Sebenello et al., 2016). Por outro lado, a autora chama a atenção para a existência de formações espontâneas nesses locais, pensadas e organizadas pelos próprios jovens, mas que passam quase despercebidas em 
grande parte das abordagens sobre o tema. São os grupos de colegas do bairro que se reúnem para jogar bola, a banda de pagode formada por amigos, etc., que vêm se configurando como importantes componentes do lazer juvenil e que, por seu caráter flexível e aberto, constituem-se como espaços propícios para o desenvolvimento do protagonismo, criatividade e autonomia.

\subsection{A TEORIA BIOECOLÓGICA DO DESENVOLVIMENTO HUMANO}

Este estudo utilizou como aporte teórico a teoria bioecológica, proposta por Bronfenbrenner, que considera o desenvolvimento como um processo de interação recíproca e dinâmica entre a pessoa e seu ambiente, equivalendo, de forma integrada, a importância de ambos dentro dos aspectos evolutivos. Dentro dessa perspectiva, quatro dimensões conceituais devem ser consideradas: o processo, a pessoa, o contexto e o tempo: (o PPCT) (Bronfenbrenner, 2001; Bronfenbrenner, \& Morris, 2006).

Considerados elementos-chave da teoria de Bronfenbrenner, os processos proximais são definidos como formas duradouras de interação entre um indivíduo ativo e as outras pessoas, objetos e símbolos que se encontram em seu ambiente imediato. A forma, o poder, o conteúdo e a direção desses processos influenciam o desenvolvimento, variando dinamicamente com as outras três dimensōes (Bronfenbrenner, \& Morris, 2006). As características da pessoa são compreendidas, ao mesmo tempo, como produtoras e produto do desenvolvimento, e foram divididas em três tipos, baseados em sua capacidade de influenciar os processos proximais:

1) caracteristicas de demanda: são as características mais perceptíveis dos indivíduos, que agem como um estímulo imediato para outra pessoa, tais como idade, gênero, cor da pele, estatura, etc.;

2) características de recurso: são construídas e internalizadas no decorrer do processo de interação da pessoa em desenvolvimento com o ambiente, podendo estar relacionadas com recursos cognitivos e emocionais, e também com recursos sociais e materiais;

3) características de força: são aquelas relacionadas à motivação, persistência, temperamento, etc., desenvolvidas a partir dos estímulos e incentivos recebidos pelo indivíduo (Bronfenbrenner, \& Morris, 2006). 
Para definir o contexto, Bronfenbrenner propôs uma divisão baseada em quatro sistemas interconectados (do mais imediato ao mais remoto):

1) microssistema: atividades, papéis e relações interpessoais da pessoa em desenvolvimento nos contextos nos quais ela estabelece relações face a face;

2) mesossistema: inter-relações entre microssistemas;

3) exossistema: contexto em que a pessoa não está presente, mas no qual ocorrem eventos que influenciam seu desenvolvimento;

4) macrossistema: qualquer cultura, subcultura ou estrutura social mais ampla, cujos membros compartilham valores, crenças, ideologias, etc. (Bronfenbrenner, $\&$ Morris, 2006).

Por fim, o tempo permite examinar as influências das continuidades e mudanças que ocorrem durante o curso de vida do indivíduo, para seu desenvolvimento. Sua análise deve ter como foco a pessoa em desenvolvimento em relação aos diversos acontecimentos de sua vida, dos mais próximos aos mais distantes (Bronfenbrenner, \& Morris, 2006).

A partir dessas considerações, este estudo teve como objetivo investigar de que modo a participação de jovens de classes populares em grupos de lazer pode influenciar seu desenvolvimento e, ainda, como os jovens avaliam a relação dessa participação no estabelecimento e manutenção dos processos proximais com seus familiares e pares.

\section{MÉTODO}

\subsection{PARTICIPANTES}

Participaram da pesquisa 21 jovens de classe popular, sendo 12 moças e 9 rapazes, na faixa etária de 15 a 19 anos, estudantes de ensino médio em uma escola da rede pública de um município metropolitano. É importante ressaltar que o termo classe popular está sendo aqui utilizado com base na caracterização biodemográfica dos participantes, considerando algumas características como: ocupação, nível de renda, formação escolar, posses, etc., levando em conta o contexto e as condições em que estão sendo analisados. 


\subsection{INSTRUMENTO}

O instrumento escolhido para a coleta de dados foi a en trevista semiestruturada, que tem como característica o uso de questões abertas e flexíveis, permitindo uma compreensão detalhada das crenças, atitudes, sentimentos, valores e motivações dos indivíduos em contextos sociais específicos (Biasoli-Alves, 1998; Gaskell, 2002). Nesse sentido, as entrevistas foram guiadas com o objetivo de compreender como a participação dos jovens em grupos de lazer pode influenciar seu desenvolvimento e a qualidade de seus relacionamentos com familiares e amigos, sendo desenvolvidas com base nos seguintes eixos temáticos:
1) caracterização biossociodemográfica dos participantes;
2) caracterização do grupo;
3) significação do grupo;
4) o grupo em relação à família;
5) o grupo em relação aos amigos.

\subsection{PROCEDIMENTOS DE COLETA DE DADOS}

Os dados foram coletados em uma escola da rede pública de um município metropolitano. Primeiramente, realizou-se contato com a coordenação da instituição, para que fossem apresentados os objetivos do estudo. Após aprovação prévia da coordenação, a pesquisadora teve acesso às turmas de ensino médio da escola, a partir de quando foi possível realizar um contato inicial com os alunos, explicando os propósitos da pesquisa e critérios para seleção dos participantes. Foram selecionados jovens que fizessem parte de algum grupo de lazer (grupos de Igreja, agremiaçôes esportivas, grupos de dança, teatro, entre outros), sendolhes garantida a voluntariedade da participação, o sigilo das informações pessoais e a possibilidade de desistência a qualquer momento. Prezou-se pela escolha de jovens que estivessem participando do grupo por um período mínimo de um ano, assegurando, assim, uma maior estabilidade das relações nesse contexto. Os pais dos alunos que concordaram com a participação de seus filhos assinaram um termo de consentimento livre e esclarecido, e os jovens, por sua vez, assinaram um termo de assentimento.

As entrevistas foram realizadas individualmente, pela própria pesquisadora, em espaço reservado disponibilizado pela escola, com duração média de 40 
minutos. Foi solicitada a anuência dos jovens investigados para que suas respostas fossem gravadas, de modo a facilitar a manutenção da atenção da pesquisadora na interação com o sujeito e a análise mais fiel dos dados coletados. Todas as entrevistas foram transcritas na íntegra.

\subsection{PROCEDIMENTOS DE ANÁLISE DE DADOS}

Os dados coletados foram avaliados qualitativamente, mediante a análise de conteúdo (Bardin, 2004), em que os conteúdos emergidos do material coletado foram organizados em categorias, as quais foram construídas a priori, a partir do modelo PPCT proposto por Bronfenbrenner:

1) o grupo como microssistema;

2) características pessoais no processo grupal; e

3) processos proximais no mesossistema: família, amigos e grupo.

\subsection{RESULTADOS E DISCUSSÃO}

\subsubsection{DADOS BIOSSOCIODEMOGRÁFICOS}

Com relação aos dados obtidos com base na caracterização biossociodemográfica dos participantes, a amostra apresenta jovens com idade média de 17 anos, estudantes de ensino médio em uma escola da rede pública, durante o período matutino, sendo 11 cursando a $3^{\mathrm{a}}$ série; 7 , a $2^{\mathrm{a}}$ série; e 3 , a $1^{\mathrm{a}}$ série. Foram identificadas diferentes configurações familiares entre os jovens investigados. Em sua maioria, os participantes (14) coabitam em famílias nucleares, sendo que 4 relataram também a presença de avós e, ou, primos na mesma casa, 4 coabitam em famílias monoparentais e 3 em famílias reconstituídas. Doze participantes souberam estipular a renda aproximada de suas famílias, que se concentrou entre $\mathrm{R} \$ 1.000,00$ a $\mathrm{R} \$ 2.000,00$. No que diz respeito ao trabalho dos pais, observa-se que as mães se encontram, principalmente, nas ocupações de dona de casa (4) e empregada doméstica (3), ou desempregadas (3); entre os pais, observa-se uma frequência maior nas ocupaçôes como comerciante (3), funcionário público (2), sendo também citadas as profissões de pedreiro, vigilante, porteiro, entre outras. Por fim, 11 jovens afirmaram estar trabalhando, em sua maioria, como adolescente aprendiz (6), e ainda, como ajudante no comércio dos pais (2), babá (1), plotador (1) e em trabalhos de filmagem e edição (1). 


\subsubsection{O GRUPO COMO MICROSSISTEMA}

Os jovens investigados participam de diferentes grupos de lazer, sendo, em sua maioria, integrantes de grupos esportivos (9), seguido pela participação em grupos de dança (6), teatro (4) e música (2). Desses grupos, 16 se organizam em instituições formais e cinco espontaneamente. Entre os grupos formais, 10 estão ligados à Igreja (1 à Igreja Católica e os outros 9 a Igrejas evangélicas), 3 a academias e 3 a projetos sociais desenvolvidos por diferentes instituições (clubes, Polícia Militar, etc.). O tempo máximo de participação no grupo foi de 10 anos e o mínimo de 1 ano, sendo que, em geral, os jovens afirmaram frequentar o grupo entre 1 e 2 anos. Quanto à frequência de encontros com o grupo, a média relatada foi de 2 a 3 vezes por semana, concentradas principalmente nos fins de semana, mas também durante a semana, no período noturno.

Por propiciarem o engajamento em atividades e interaçôes face a face, com frequências regulares de participação, os grupos de lazer são compreendidos como microssistemas dentro da perspectiva bioecológica. Nesse sentido, as atividades realizadas nesses espaços, a importância afetiva das pessoas envolvidas bem como os sentidos atribuídos às experiências neles desenvolvidas são relevantes para que possamos apreender os processos ali estabelecidos. Nas verbalizações dos jovens, é possível identificar como esses processos ocorrem nos grupos em que participam. As relações de afinidade com os demais integrantes do grupo foram evidenciadas pelos sujeitos investigados, que o apontaram como local favorável para conhecer pessoas com quem se identificam e onde podem conversar sobre assuntos de seu interesse. A participante F3, 18 anos, integrante de um grupo de futebol feminino, por exemplo, relata que o grupo é o local onde ela se sente mais à vontade para conversar sobre futebol, pois todas as meninas gostam e se interessam pelo assunto. De um modo geral, as interaçôes estabelecidas dentro do grupo foram definidas pelos participantes a partir das expressões "relaxantes", "divertidas", "agradáveis" e "prazerosas", características que, segundo Elias e Dunning (1996), usualmente se fazem presentes nos momentos de lazer.

Em suas falas, nota-se o estabelecimento de relações afetivas dentro do grupo, que é apontado pelos sujeitos como uma família, um local onde fizeram grandes amizades, onde encontram pessoas que lhes dão apoio e que se mostram preocupadas quando estão com algum problema. Entre os participantes dos grupos formais, esse afeto aparece também direcionado ao(s) líder(es) do grupo, visto como alguém que está sempre os incentivando, colocando "pra cima", com quem eles podem sempre contar, que se interessa em saber como eles estão se sentindo e se está tudo bem em casa ou na escola. 
Outro ponto importante, também abordado pelos participantes, diz respeito à possibilidade proporcionada pelo grupo de se desenvolverem novas habilidades, manifestada de diversas formas: quando aprendem um novo passo de dança, um golpe de luta, a tocar um novo instrumento, ou ainda, quando participam de oficinas, criam coreografias, disputam campeonatos, entre outros. Prates (2012) enfatiza que os grupos de lazer (seja de teatro, dança, música, etc.) podem ajudar a descobrir novos talentos e desenvolvê-los, abrindo um campo desconhecido até então de possibilidades para os jovens. A paixão pela música, descrita pelo jovem M1, 17 anos, levou-o ao grupo para aprender a tocar um instrumento e agora ele vê em sua experiência dentro do grupo a chance de alcançar uma formação profissional: "Eu sempre me interessei por música, sabe? Aí, eu quis aprender a tocar teclado [...] agora, eu pretendo entrar na Fames, ${ }^{1}$ fazer a prova nesse final de ano e ser formado em música”.

Observa-se que as relações estabelecidas dentro do grupo se estendem para outros contextos e situações, o que pode ser percebido nos relatos a respeito das viagens realizadas com o grupo, dos encontros com os amigos do grupo em outros ambientes, tais como pizzaria, cinema, etc.: "A gente viaja para vários lugares [...] Guarapari, Santa Teresa, Pedra Azul. ${ }^{2}$ Nas viagens, rola música, dança, e a gente aproveita para ir, juntos, conhecer os lugares que a gente vai" (F10, 16 anos).

Um expressivo número de jovens relatou participação nos grupos ligados à Igreja. Franch (2000) ressalta que a falta de políticas públicas mais efetivas no âmbito do lazer faz com que as iniciativas nesse campo partam, principalmente, das instituições religiosas, daí a predominância de grupos juvenis nesses ambientes. Atualmente, um crescente número de investigações tem apontado que o envolvimento religioso exerce papel-chave no desenvolvimento saudável na juventude (Furrow, King, \& White, 2004; Hopkins et al., 2007; Marques, Cerqueira-Santos \& Dell'Aglio, 2011) e age como fonte de suporte, encorajamento, satisfação e valores (Pargament, \& Park, 1995; Wagener, Furrow, King, Leffert, \& Benson, 2003).

Para Marques, Cerqueira-Santos e Dell'Aglio (2011), a religião estimula a formação de grupos, nos quais os jovens se inserem e vivenciam aspectos positivos. Esses grupos, apesar de ligados a Igrejas, podem ser de diversos tipos: teatro, hip-hop, balé contemporâneo, música, entre outros. Nas falas dos participantes, é possível perceber a presença do discurso religioso nesses meios, mas também uma tentativa de ir além desse discurso, buscando maneiras de estar em sintonia com os interesses da juventude: "Porque adolescente precisa

\footnotetext{
${ }^{1}$ Faculdade de Música do Espírito Santo.

${ }^{2}$ Localidades no Estado do Espírito Santo.
} 
disso, de coisas que deixem eles à vontade, não é só aquela coisa da Igreja ficar falando, falando, falando, entende?" (F2, 16 anos). Os jovens relatam que, nesses grupos, eles participam de oficinas, apresentam-se em diferentes lugares (tanto em outras Igrejas como em festividades de diversas cidades) e buscam inspirações em outros grupos, não necessariamente ligados a instituições religiosas: "Lá no nosso grupo, tem rapper, tem bit box, aquele cara que faz o som com a boca [...] Lá tem muita coisa, é muito irado" (M8, 19 anos). A oportunidade oferecida pela Igreja é também, muitas vezes, a única forma de esses jovens fazerem algo que gostam, como no depoimento de F5, 17 anos: "Ah, é que eu sempre gostei de dançar, meu sonho sempre foi fazer balé, só que eu nunca pude entrar. Minha mãe não tinha como pagar, aí eu nunca entrei [...] Aí eu vi nesse grupo da Igreja a oportunidade de estar dançando".

A predominância dos jovens em grupos religiosos provavelmente está relacionada ao fato de serem esses ambientes, sobretudo nos bairros populares, os que mais lhes oferecem oportunidades. São pouquíssimos ou quase inexistentes os espaços de lazer oferecidos pelas escolas ou mesmo em outros espaços das comunidades em que moram. Entre os jovens da amostra, somente uma alegou participar de um grupo na escola, sendo que a instituição disponibilizava apenas o espaço. Eram os próprios jovens que se organizavam e, mesmo assim, foram destacados alguns problemas: "O grupo acontece aqui na escola, mas nós mesmos que nos viramos [...] Não tem muito apoio [...] Às vezes, tem um professor que ajuda a gente, mas nem sempre pagam a passagem pra ele poder vir, mas tirando isso, a gente se vira direitinho" (F6, 18 anos, participante de grupo de handebol).

Dentro de suas comunidades, foram relatadas apenas formações espontâneas, que contam com a força e a disposição dos próprios jovens, que, muitas vezes, improvisam espaços na própria rua, na falta de locais apropriados. Urnau e Zanella (2009) e Sebenello, Keitel e Kleba (2016), em estudo com jovens em situações de risco, também identificaram a escassez de projetos sociais nas comunidades os quais, de fato, envolvam e integrem os jovens em sua concepção e desenvolvimento. Quando existentes, os projetos acabam se desenvolvendo em condições precárias e pouco animadoras.

\subsubsection{CARACTERÍSTICAS PESSOAIS NO PROCESSO GRUPAL}

$\mathrm{Na}$ teoria bioecológica, as características da pessoa são vistas como produtoras e produto do desenvolvimento, ou seja, elas tanto influenciam o grupo como são também influenciadas por ele. Por exercer influência significativa na forma, conteúdo e direção dos processos, o gênero é uma das características que recebe destaque nos estudos de Bronfenbrenner (Bronfenbrenner, \& Morris, 2006). 
Traçando uma análise a partir dessa característica, observa-se o seguinte cenário: entre os meninos, a maior participação se deu nos grupos esportivos (5), seguido por grupos musicais (2) e grupos de dança (2). Entre as meninas, houve maior equilíbrio, sendo 4 participantes em grupos de teatro, 4 em grupos esportivos e 4 em grupos de dança. Dos grupos em que as meninas participam, 7 são ligados à Igreja, enquanto, entre os meninos, apenas 2. Alguns estudos internacionais apontam uma tendência significativa de as meninas estarem mais envolvidas em grupos religiosos do que os meninos (Bryant, 2007; Smith, \& Denton, 2005), o que também foi percebido por Marques, Cerqueira-Santos e Dell'Aglio (2011), em estudo sobre religiosidade e identidade positiva na adolescência, em que a identificação com atividades religiosas foi mais alta entre meninas do que entre meninos.

Em relação à participação em grupos esportivos, as falas das meninas apontam principalmente para uma visão do esporte como forma de relaxar, fugir da rotina, desestressar após o dia de estudo/trabalho. Já entre os meninos, o discurso mais notável é o da competitividade. Para eles, o grupo facilita a participação em campeonatos e, ou, jogos com outros grupos. Os meninos apresentam ainda a ideia de que a permanência deles no grupo pode proporcionar, no futuro, a chance de se tornarem profissionais no esporte que praticam: "Agora no domingo, eu lutei no campeonato estadual. Tem medalha, premiação, eu fiquei em $2^{\circ}$ lugar, ganhei medalha pela primeira vez [...] E se eu continuar bem, quem sabe, eu me torne profissional" (M2, 17 anos). Para Gáspari e Schwartz (2001), as características de competitividade e prestígio pessoal são culturalmente associadas ao esporte e tidas em nossa sociedade como tipicamente masculinas.

Nota-se ainda uma maior participação das meninas em grupos formais em relação aos meninos. Essa tendência certamente está relacionada ao fato de esses grupos possibilitarem um maior controle de suas vivências no tempo livre, uma vez que eles ocorrem em locais específicos, com dias e horários fixos. Como apontam os estudos, as meninas geralmente são estimuladas a desenvolver atividades na própria casa ou em espaços onde seja possível exercer maior vigilância, já que, como explica Franch (2000), há uma grande preocupação, principalmente por parte dos pais, para que elas não fiquem "faladas" e nem se envolvam em situações consideradas "perigosas" (Brenner, Dayrell, \& Carrano, 2005; Franch, 2000; Oliveira, 2015; Traverso-Yépes, \& Pinheiro, 2005).

Quando falamos nos usos do tempo livre entre jovens de classes populares, é comum que prevaleçam representações enfatizando a falta de oportunidades para se vivenciar esse tempo. Contudo, ainda que tenham um acesso limitado aos circuitos de lazer, que se encontram cada vez mais atrelados a uma perspectiva de consumo, percebemos, nas falas desses jovens, a presença de características de 
força atuando positivamente sob suas interações nesse contexto. São jovens que, na maioria das vezes, estudam e trabalham, residem em bairros com pouquíssima infraestrutura e escassez de equipamentos de lazer, o que não os impede de se reunir, fazer o que gostam e criar formas específicas de diversão. Eles relatam que, muitas vezes, acordam bem cedo para estar com o grupo, adaptam locais para realizar os encontros, organizam eventos com o grupo, criam coreografias, etc. A participante F12, 16 anos, teve paralisia cerebral devido a problemas em seu nascimento e não tem o movimento das pernas. Ela participa de um grupo de natação e gasta aproximadamente uma hora para chegar ao clube, onde se reúne com o grupo de segunda a sábado. A jovem vê no grupo uma possibilidade de superação e de inclusão na sociedade. O grupo atua, então, reforçando características de força que já estavam presentes em F12, visto que a incentiva, possibilita o aprendizado de novas habilidades e cria recursos para seu desenvolvimento. Como destacam Bonato, Sarriera e Wagner (2012), experiências transformadoras no âmbito do tempo livre podem influenciar nas percepçôes que os jovens têm de si e são fundamentais para que eles possam se projetar futuramente.

A partir dos processos estabelecidos dentro do grupo, os jovens perceberam mudanças em suas características pessoais, entre as quais, as mais citadas foram: a superação da timidez e o fato de terem se tornado mais comunicativos:

Por exemplo, eu sempre fui muito tímida. Aí, quando eu entrei lá, foi muito diferente. O pessoal já chega, te abraça, conversa e tal. Aí eu fui percebendo que eu fui mudando isso em mim. Eu já tomo a iniciativa de conversar com a pessoa, entendeu? (F1, 19 anos).

Entre os participantes de grupos esportivos, foram relatadas ainda mudanças nas características físicas: emagrecimento, melhoras na saúde, no condicionamento físico, resistência, etc. Já entre os integrantes dos grupos formais, as mudanças estiveram também relacionadas às ideias de responsabilidade e disciplina, o que pode ser entendido pelo fato de esses grupos se desenvolverem com base em regras e estruturas mais rígidas e ainda se encontrarem muito vinculados a uma noção de controle do tempo, o que acaba repercutindo no discurso dos jovens.

\subsubsection{PROCESSOS PROXIMAIS NO MESOSSISTEMA: FAMÍLIA, AMIGOS E GRUPO}

A terceira categoria abrange as inter-relações estabelecidas entre o grupo e outros dois contextos de grande importância na vida dos jovens: família e amigos. A família é considerada por Bronfenbrenner (1988) como o principal 
microssistema para o desenvolvimento, pois é nela que ocorrem as interações mais diretas e as experiências mais significativas para os indivíduos. Seu funcionamento interno, ou seja, a forma como os processos proximais ocorrem no ambiente familiar, recebe influências diretas e indiretas de outros contextos. Nesse sentido, Senna e Dessen (2012) explicam que, conforme o jovem começa a participar de outros microssistemas e a ampliar sua rede de relações interpessoais, formam-se novas relações e influências interdependentes entre a família e seus demais contextos de interações proximais.

Nas falas dos jovens investigados, observa-se que a participação no grupo acaba proporcionando uma ampliação das interações com seus familiares, o que é percebido por eles quando os pais se organizam para assistir aos filhos nos eventos promovidos pelo grupo (campeonatos, apresentações de música, dança, etc.), nas conversas que têm em casa a respeito das situaçôes vivenciadas no grupo ou mesmo quando conseguem levar familiares para participarem do grupo, o que se torna uma forma a mais de estarem juntos. A participante F4, 18 anos, fala sobre a presença de sua mãe em sua primeira apresentação teatral:

Na minha primeira vez no palco, no teatro de Viana, ${ }^{3}$ minha mãe foi me ver atuar. Aí eu cheguei, olhei pra plateia assim. Ela tava na primeira fila. Aí eu tinha que entrar e fazer umas perguntas pra minha amiga que já tinha entrado. Nossa, eu tremi, mas eu fiquei muito feliz de ver minha mãe lá! Me deu motivação pra continuar. Nossa, foi muito bom! Acho que minha mãe sentiu orgulho. Ela me deu um abraço tão bom assim, no final!

Os jovens relatam ainda a importância dos incentivos que recebem da família para permanecerem no grupo, o que lhes dá disposição e motivação. Esses incentivos são percebidos de várias formas: quando os pais permitem que eles viajem com o grupo, reafirmando suas relações de confiança, no esforço dos pais quando precisam de dinheiro para as viagens, campeonatos, etc., por meio de palavras motivadoras, reconhecendo e valorizando o papel do filho no grupo, entre outros. Os participantes M8 e F6 descrevem, de maneiras diferentes, a forma como percebem os incentivos por parte da família:

Uma vez, lá no grupo de hip-hop, eu fui dar um mortal e errei. Minha mãe viu. Depois ela veio pra mim e falou: "Pode deixar que, na próxima, você consegue" (M8, 19 anos).

Meu pai sempre vem, me pega, leva pro grupo, aí eu falo, "Pai, vou sair tal hora". Ele vai e me busca. Se a gente precisa de alguma coisa lá no grupo, ele se aperta e compra (F6, 18 anos).

De um modo geral, as verbalizaçôes dos jovens demonstram a importância da qualidade de suas interações com a família e não só da intensidade de contato, ${ }^{3}$ Município do Estado do Espírito Santo. 
que acaba se reduzindo sobretudo nessa faixa etária (Bronfenbrenner, \& Morris, 2006). Com base nas falas dos participantes, observa-se que o estabelecimento de processos positivos no ambiente familiar tende a repercutir nos demais microssistemas em que os jovens participam, com pais engajados e ativos nesses contextos, o que contribui de maneira significativa para seu desenvolvimento.

As competências pessoais e habilidades desenvolvidas pelos jovens dentro dos grupos também influenciam suas relações no contexto familiar. Os sujeitos da pesquisa enfatizam que o grupo, ao propiciar o convívio com pessoas de diferentes personalidades, permite que eles aprendam a respeitar diferenças, a ouvir e ser ouvidos, o que acaba refletindo em suas condutas no ambiente familiar. F4, 18 anos, participante de um grupo teatral, relata que uma prática recorrente no grupo, voltada para o relaxamento e meditação, foi fundamental na qualidade do relacionamento com sua mãe, uma vez que a ensinou a pensar e refletir antes de tomar atitudes precipitadas.

Os amigos são outro grupo de extrema importância e de grande impacto na vida dos jovens. Bronfenbrenner (1985) ressalta que, com as mudanças significativas no âmbito familiar (mães que trabalham em tempo integral, famílias monoparentais, etc.), os jovens tendem cada vez mais a viver em um mundo de pessoas de sua idade e que as influências dos amigos têm se tornado até mesmo mais significativas que a dos pais. Nesse sentido, os jovens investigados ressaltam alguns pontos principais a respeito dos impactos de sua participação nos grupos de lazer em relação aos processos proximais estabelecidos com os amigos:

1) primeiramente, os jovens apontam que as mudanças em suas características pessoais favorecidas por sua participação nos grupos, entre as quais se sobressaem a superação da timidez e o fato de terem se tornado mais comunicativos, tiveram influência decisiva em suas interações com os amigos, potencializando essas relaçôes;

2) há influências dos amigos na escolha do grupo, e foram eles os mais citados quando questionamos os jovens sobre quem os levou até o grupo;

3) por fim, o reconhecimento dos pares (seja indo assisti-los nas apresentações dos grupos, demonstrando interesse pelo grupo ou mesmo indo junto participar) faz com que esses jovens se sintam prestigiados e valorizados, funcionando como uma forma de autoafirmação.

Como explicam Santos e Fernandes (2011), na relação com os iguais, o jovem vai construindo seu autoconceito e, nesse sentido, as percepções que 
os outros colegas têm sobre ele se apresenta como fator fundamental para seu desenvolvimento. A participante F2, 16 anos, descreve como se sentiu com a presença de um amigo em uma de suas apresentações no grupo de dança:

Uma vez, eu convidei um amigo meu daqui da escola, que mora lá em Cariacica ${ }^{4}$, pra ir assistir minha apresentação de dança na igreja. Aí foi ele e mais uma amiga minha também. Nossa, eu me senti muito especial naquele dia! Nossa, fiquei muito feliz!

Dentro da perspectiva bioecológica, considera-se que as chances maiores de desenvolvimento estão presentes nos indivíduos que se relacionam com pessoas engajadas em suas vidas, com as quais desenvolvem relações de cuidado e afeto. Assim, o caráter transformador dos grupos de lazer está certamente ancorado em sua integração com os outros sistemas em que os jovens se inserem (Prates, 2012). O incentivo, apoio e participação da família, dos amigos, etc., são fundamentais para que os grupos de fato propiciem o estabelecimento de processos proximais que tragam resultados positivos no desenvolvimento e se constituam como recurso favorecedor para o desenvolvimento desses jovens.

\section{CONSIDERAÇÕES FINAIS}

Este estudo investigou as influências da participação em grupos de lazer no desenvolvimento de jovens de classes populares. Os dados apresentados demonstram que os grupos se configuram como microssistemas na vida desses jovens visto que possibilitam o engajamento em atividades e interaçôes face a face, com frequências regulares de participação e entre pessoas significativas. A socialização em diferentes microssistemas para além do contexto familiar propicia aos jovens uma ampliação de sua rede de relações interpessoais e, como apontam Senna e Dessen (2012), os recursos provenientes desses ambientes não podem ser negligenciados, já que exercem influência significativa em seu desenvolvimento.

Nesse sentido, partindo dos pressupostos da teoria bioecológica, os resultados desta pesquisa sinalizam que as trajetórias desenvolvimentais positivas estão associadas a uma interação recíproca e dinâmica entre os recursos pessoais dos jovens (talentos, força, interesses) e o estabelecimento de relações positivas em seus contextos de interaçôes proximais, que promovam o desenvolvimento de habilidades, a participação nas decisões e que, acima de tudo, saibam reconhecêlos em suas peculiaridades.

A ausência de políticas públicas mais efetivas no âmbito do lazer juvenil faz com que esses grupos sejam organizados, principalmente, a partir de instituiçôes

\footnotetext{
${ }^{4}$ Município do Estado do Espírito Santo.
} 
religiosas. São pouquíssimos ou quase inexistentes os espaços de lazer oferecidos pelas escolas ou mesmo em outros locais nas comunidades onde esses jovens moram. A falta de grupos de lazer, sobretudo na escola, foi evidenciada pelos jovens investigados que apontaram a necessidade de uma maior integração desses grupos ao contexto escolar.

Além disso, na amostra pesquisada, não houve participação em grupos oferecidos pelo governo. Esse cenário demonstra a urgência de maiores investimentos em políticas públicas de lazer juvenil, para que estas de fato se façam presentes na vida desses jovens e que saibam, acima de tudo, reconhecêlos como atores estratégicos do seu próprio desenvolvimento, com participação ativa nas ações a eles destinadas, distanciando-se, assim, das perspectivas que visam ao controle e ocupação de seu tempo livre.

Vale ressaltar que este estudo é parte integrante do Estudo nacional sobre fatores de risco e proteção na juventude brasileira, vinculado à Associação Nacional de Pesquisa e Pós-Graduação em Psicologia (Anpepp), e apresenta algumas limitações, sobretudo por não se tratar de uma pesquisa longitudinal, o que acarretou a impossibilidade de análise da variável tempo, dentro do modelo PPCT proposto por Bronfenbrenner. Sugere-se que as pesquisas futuras possam abarcar as variáveis não contempladas neste estudo, como uma análise comparativa entre dois períodos distintos e ainda a inserção nos contextos família e amigos, de modo a confirmar as percepções dos jovens sobre as influências dos grupos de lazer no relacionamento com esses contextos. 


\section{REFERENNCIAS}

Aquino, L. (2009). A juventude como foco das políticas públicas. In J. A. Castro, L. M. Aquino, \& C. C. Andrade (Orgs.), Juventude e politicas sociais no Brasil. (pp. 25-39). Brasília: IPEA. Recuperado a partir de http://www.ipea.gov.br/ portal/images/stories/PDFs/livros/livro_juventudepolitica.pdf

Bardin, L. (2004). Análise de conteúdo. Lisboa: Edições 70.

Biasoli-Alves, Z. M. M. (1998). A pesquisa em Psicologia: análise de métodos e estratégias na construção de um conhecimento que se pretende científico. In Z. M. M. Biasoli-Alves, \& G. Romanelli (Orgs.), Diálogos metodológicos sobre prática de pesquisa. (pp. 135-157). Ribeirão Preto: Legis Summa.

Bonato, T. N., Sarriera, J. C, \& Wagner, A. (2012). Hábitos de lazer e autoconceito em adolescentes. In J. C. Sarriera, \& A. C. Paradiso (Orgs.), Tempo livre e lazer na adolescência: promoção de saúde, intervenção e pesquisa. (pp. 125-153). Porto Alegre: Sulina.

Brenner, A. K., Dayrell, J., \& Carrano, P. (2005). Culturas do lazer e do tempo livre dos jovens brasileiros. In H. W. Abramo, \& P. P. M. Branco (Orgs.), Retratos da juventude brasileira: análises de uma pesquisa nacional. (pp. 175214). São Paulo: Fundação Perseu Abramo.

Bronfenbrenner, U. (1985). The future of childhood. In V. Greaney (Ed.), Children: needs and rights. (pp. 167-186). New York: Irvington.

Bronfenbrenner, U. (1988). Strengthening family systems. In E. F. Zigler, \& M. Frank (Eds.), The parental leave crisis: toward a national policy. (pp. 143-160). New Haven: Yale University Press.

Bronfenbrenner, U. (2001). The bioecological theory of human development. In U. Bronfenbrenner (Ed.), Making humanbeings human: bioecological perspectives on human development. (pp. 3-15). Thousand Oaks: Sage.

Bronfenbrenner, U., \& Morris, P. (2006). The bioecological model of human development. In W. Damon, \& R. M. Lerner (Eds.), Handbook of child psychology: theoretical models of human development. (pp. 793-828). New York: John Wiley \& Sons.

Bryant, A. N. (2007). Gender differences in spiritual development during the college years. Sex Roles, 56, 835-846. 
Dutra-Thomé, L., \& Koller, S. (2014). Emerging Adulthood in Brazilians of differing socioeconomic status: transition to adulthood. Paidéia, 24(59), 313322.

Elias, N., \& Dunning, E. (1996). Deporte y ocio en el proceso de la civilización. México: Fondo de Cultura Económica.

Franch, M. (2000). Tardes ao léu: um ensaio etnográfico sobre o tempo livre entre jovens de periferia. (Dissertação de Mestrado). Universidade Federal de Pernambuco, Recife. Recuperado a partir de http://www.bdae.org.br/dspace/ bitstream/123456789/1967/1/tese.pdf

Furrow, J. L., King, P. E., \& White, K. (2004). Religion and positive youth development: identity, meaning and prosocial concerns. Applied Development Science, 8(1), 17-26.

Gaskell, G. (2002). Entrevistas individuais e grupais. In M. W. Bauer, \& G. Gaskell (Orgs.), Pesquisa qualitativa com texto, imagem e som: um manual prático. (pp. 64-89). Petrópolis: Vozes.

Gáspari, J. C., \& Schwartz, G. M. (2001). Adolescência, esporte e qualidade de vida. Motrix, 7(2), 107-113.

Hopkins, G. L., McBride, D., Marshak, H. H., Freier, K., Stevens, J. V., Kannenberg, W., . . . Duffy, J. (2007). Developing healthy kids in healthy communities: eight evidence-based strategies for preventing high-risk behavior. Medical Journal of Australia, 186(10), S70-S73.

Marques, L. F., Cerqueira-Santos, E., \& Dell'Aglio, D. D. (2011). Religiosidade e identidade positiva na adolescência. In D. D. Dell'Aglio, \& S. H. Koller (Orgs.), Adolescência e juventude: vulnerabilidade e contextos de proteção. (pp. 78-108). São Paulo: Casa do Psicólogo.

Marques, L. F., Dell'Aglio, D. D., \& Sarriera, J. (2009). O tempo livre na juventude brasileira. In R. M. C. Libório, \& S. H. Koller (Orgs.), Adolescência e juventude: risco e proteção na realidade brasileira. (pp. 79-106). São Paulo: Casa do psicólogo.

Miranda, L. L., Souza Filho, J. A., \& Santiago, M. V. (2014). A relação lazer e mídia entre adolescentes e jovens de escolas públicas em Fortaleza/CE. Psicologia Argumento, 32(79), 29-43.

Oliveira, E. F. (2015). Vivências de lazer e tempo livre: estudos com jovens de classe 
média. (Dissertação de Mestrado). Programa de Pós-Graduação em Psicologia, Universidade Federal do Espírito Santo, Vitória.

Pargament, K., \& Park, C. L. (1995). Merely a defense? The variety of religious mean and ends. Journal of Social Issues, 51, 13-32.

Prates, M. A. (2012). Conhecer, explorar e desenvolver atividades para o tempo livre: um jeito próprio de ver a vida. In J. C. Sarriera, \& A. C. Paradiso (Orgs.), Tempo livre e lazer na adolescência: promoção de saúde, intervenção e pesquisa (pp. 61-95). Porto Alegre: Sulina.

Santos, C. P., \& Fernandes, D. V. (2011). A socialização de consumo e a formação do materialismo entre os adolescentes. Revista de Administração Mackenzie, 12(1), 169-203.

Schutz, F., Calza, T., \& Howes, G. (2012). Protagonismo juvenil e tempo livre. In J. C. Sarriera, \& A. C. Paradiso (Orgs.), Tempo livre e lazer na adolescência: promoção de saúde, intervenção e pesquisa. (pp. 45-60). Porto Alegre: Sulina.

Sebenello, D. C., Keitel, L., \& Kleba, M. E. (2016). Práticas de lazer e espaços públicos de convivência como potência protetiva na relação entre juventude e risco. Katálysis, 19(1), 53-63.

Senna, S. R., \& Dessen, M. A. (2012). Contribuições das teorias do desenvolvimento humano para a concepção contemporânea da adolescência. Psicologia: Teoria e Pesquisa, 28(1), 101-108.

Smith, C., \& Denton, M. L. (2005). Soul searching: the religious and spiritual lives of American teenagers. New York: Oxford University Press.

Traverso-Yépez, M. A., \& Pinheiro, V. S. (2005). Socialização de gênero e adolescência. Estudos feministas, 13(1), 147-172.

Urnau, L. C., \& Zanella, A. V. (2009). Quatro jovens, um projeto social: espaços de (des)encontros. Arquivos Brasileiros de Psicologia, 6(1), 84-99.

Wagener, L. M., Furrow, J. L., King, P. E., Leffert, N., \& Benson, P. (2003). Religious involvement and developmental resources in youth. Review of Religious Research, 44(3), 271-284. 